\title{
Introduction to Bridge Construction in a Mountainous City
}

\author{
Xiaoxia Zhai ${ }^{1}$ \\ ${ }^{1}$ Chongqing Jiaotong University, China \\ Correspondence: Room 105, Unit 2, Building 12, Knowledge Garden Community, Chongqing Jiaotong \\ University, Chongqing, China. E-mail: 286026317@qq.com
}

Received: March 28, 2014

doi:10.5539/mas.v9n8p99
Accepted: May 7, 2015

Online Published: July 27, 2015

URL: http://dx.doi.org/10.5539/mas.v9n8p99

\begin{abstract}
Bridges in a mountainous city are different in style from other bridges. They are grand in opening and closing and are often recognized as important symbols of a city. Together with other elements, they form beautiful scenery of a mountainous city. This paper focuses on Chongqing, a representative mountainous city to study and analyze characteristics and features of bridges in a mountainous city, learn from experience in designing bridges in a mountainous city and provide theoretic reference for future bridge construction in a mountainous city.
\end{abstract}

Keywords: Mountainous city, features of bridge in a city, bridge design

\section{Introduction}

Bridge Construction in a Domestic Mountainous City. In Western China where mountains are gathered together, most mountainous cities are built along rivers, for which typical examples are given to Chongqing City and its other cities like Wanzhou City and Peiling City. In addition, cities that are mountainous include Yibin City and Panzhihua City in Sichuan Province, Guiyang City in Guizhou Province, Nanning City in Guangxi Province, and Hong Kong, a mountainous city built along mountains and seas in the coast of South China.

\subsection{Brides of Chongqing}

Chongqing City locates between Zhongliang Mountain and Tongluo Mountain and in river valleys and hilly areas where the Jialing River and the Yangtze River flow over. It is built by relying upon mountains, with roads being uneven and buildings well-arranged. Therefore, it is recognized as the largest and the most famous mountainous city in China. Major rivers flowing through Chongqing City are the Yangtze River, the Jialing River, the Wujiang River, the Fujiang River, Qijiang River, Daninghe River, etc. Main stream of the Yangtze River flows through the whole city from west to east, and its flow path is $665 \mathrm{~km}$ long; it passes three anticlines of Wushan Mountain, creating famous Qutang Gorge, Wuxi Gorge, and Xiling Gorge (located in Hubei Province), i.e., the Three Gorges on the Yangtze River. The Yangtze River and the Jialing River flows through the main urban zone of Chongqing City.

\section{(1) Jiayue Bridge}

Jiayue Bridge is a Y type extradosed cable-stayed bridge. Its main bridge is 778 meters long and designed with dual 6-lane carriage and speed per hour of $80 \mathrm{~km}$. Jiayue Bridge is structured with two stories, the upper storey for vehicles and the lower storey for pedestrians. At each side of the road, there is a $3.5 \mathrm{~m}$ wide "sightseeing corridor", which is first seen in China. At the two bridge towers, there will be more "sightseeing balconies", 4 inn total, each being about over $20 \mathrm{~m}^{2}$. Citizens can take a walk on the sightseeing corridor and stand for sightseeing. 


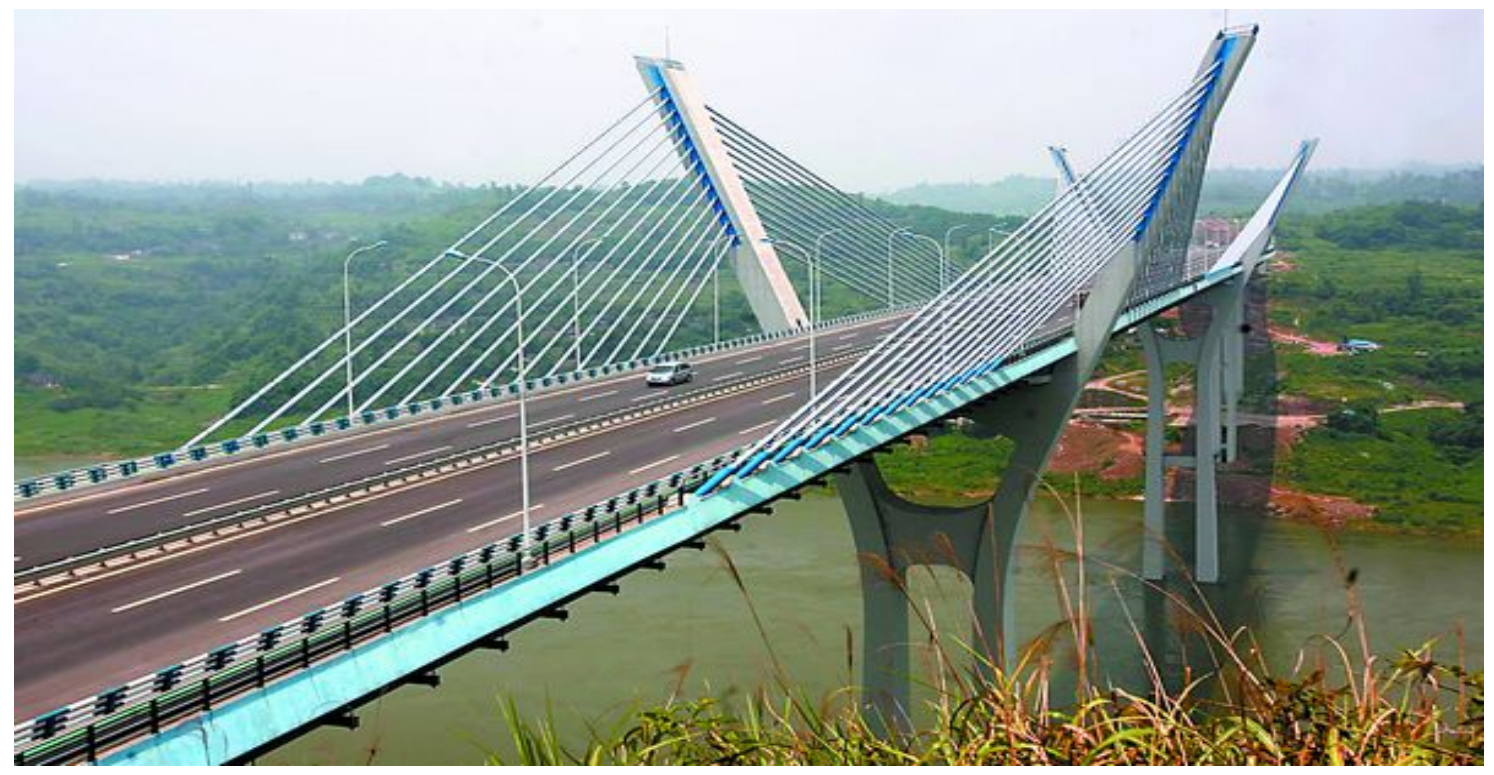

Figure 1. Jiayue Bridge

(2) Chaotianmen Yangtze River

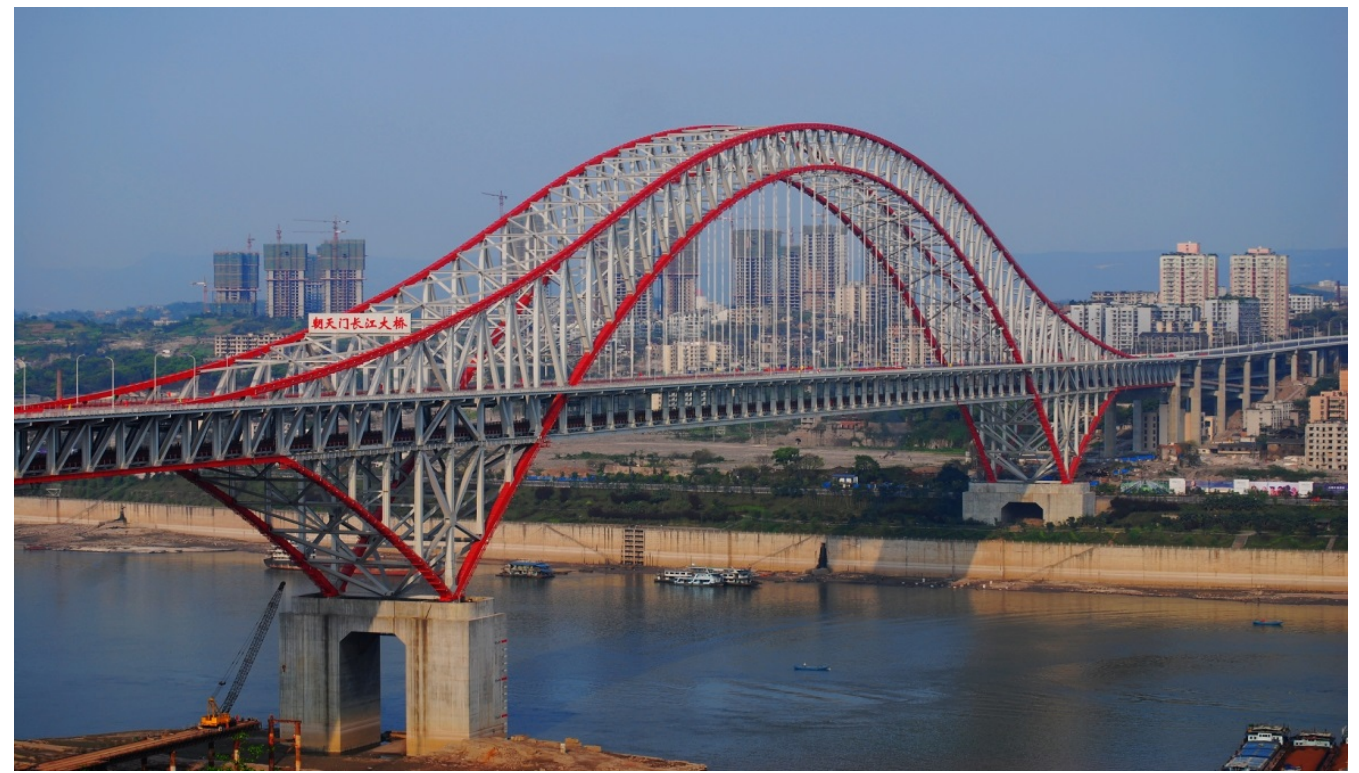

Figure 2. Chongqing Chaotianmen Yangtze River

Chongqing Chaotianmen Yangtze River locates in Wangjiatuo River Section of the Yangtze River, about $2.4 \mathrm{~km}$ on the downstream of the junction between the Jialing River and the Yangtze River, in the central business district of the main urban zone of Chongqing and on the east to west rapid transit radiated from the main urban area of Chongqing City.

As an extra-large arch bridge for both road and pathway, the bridge is of double-deck type, with the upper deck designed with dual 6-lane carriage and the lower deck designed with 2 reserving lanes and 2 dual traffic rails. The bridge is $1.74 \mathrm{~km}$ long in total. Its main bridge adopts three-span continuous steel truss tied arch bridge $(190 \mathrm{~m}+552 \mathrm{~m}+790 \mathrm{~m})$; the main bridge is $36.5 \mathrm{~m}$ wide, the truss is $29 \mathrm{~m}$ wide; the two side spans are structured with trussed beams of variable height; the mid-span is structured with steel truss tied arch. The height between arch top and middle support point is $142 \mathrm{~m}$, arch rib's lower bottom chord adopts second-degree parabola, vector height is $128 \mathrm{~m}$ and rise-span ratio is 1/4.3125; arch rib's upper chord also adopts second-degree parabola and it smoothly transits to side span's upper chord line through a circular curve $(\mathrm{R}=700 \mathrm{~m})$. The main truss adopts $\mathrm{N}$ 
type truss of variable height, arch rib's truss mid-span is $14 \mathrm{~m}$ high, and truss height at the middle support point is $73.13 \mathrm{~m}$ high (of which the arch rib's reinforced chord is $40.65 \mathrm{~m}$ high) and the truss height at side-span's support point is $11.83 \mathrm{~m}$.

Technically, Chaotianmen Yangtze River is the first flying swallow multi-rib steel truss mid-level arch bridge with the main span of $552 \mathrm{~m}$. It is the largest one among similar bridges in span and has successfully developed $145000 \mathrm{KN}$ anti-shock support base of the largest tonnage in the world. The bridge combines tied rod for steel structure and pre-stressed tied rod; structurally, steel structure tie rod is part of steel truss girder and its surface coincide with with the main truss surface. The connecting structure between tie rod and main truss arch is simple, with clear load bearing. Besides, this bridge adopts deck unit erection crane, and cable stayed knotting technology, as well as the theory of raising beam elevation to enable the main bridge to rotate, so as to realize arch first, beam second and zero stress closure mode, which is the first example in the world and the bridge line is easily guaranteed.

(3) Caiyuanba Yangtze River Bridge

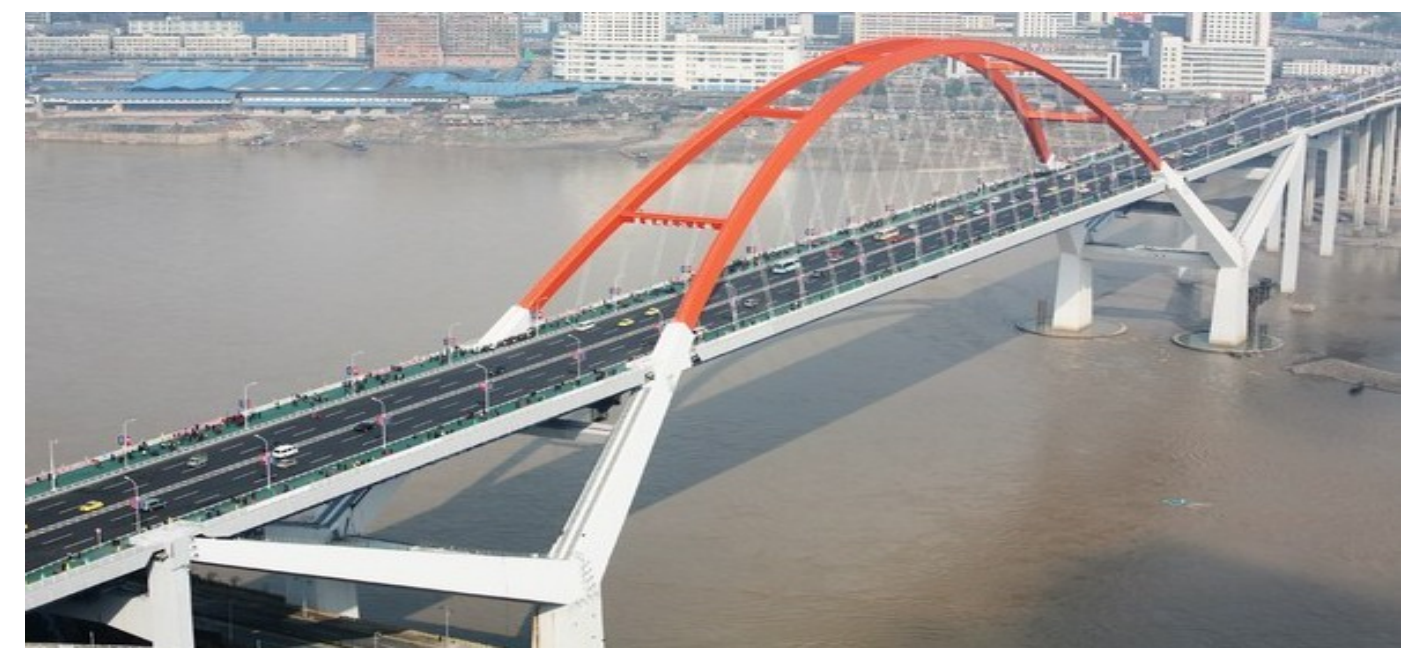

Figure 3. Caiyuanba Yangtze River Bridge

Chongqing Caiyuanba Yangtze River Bridge is a large-span arch bridge used for both public transport and urban light rail. Its main span is $240 \mathrm{~m}$, enabling it to be the arch bridge of the second largest span. Its steel structure is 18,000 tons in total. It is a center-supported zero thrust steel pipe concrete tie rod arch bridge in structure and a modern bridge that has integrated various new bridge structure types (e.g. steel pipe arch, steel box girder and steel truss girder) and scientific and technological achievements.

\section{Features of Bridges in Mountainous Cities at Home and Abroad}

We can tell that main features of bridges in mountainous cities are as follows, through analyzing bridges in mountainous cities at home and abroad:

(1) Bridges in a mountainous city must be planned according to urban zone road network of the mountainous city. Layout of a mountainous city will have a great impact upon traffic of a mountainous city. In a mountainous city, roads are built by using mountains; complicated topography, landform and geology would affect setting-out and layout of roads of a mountainous city.

(2) In the urban central zone of a large mountainous city, bridges would undertake complicated loads; affected by high-rise buildings in the city, wind direction is uncertain and wind flows at a relatively high speed; there are too many decorative objects, producing relatively high decoration load; water velocity is relatively high; anti-collision requirements of bridge piers are high. Bridge body is usually light and thin; most of it adopt steel girder as main girder, which brings high flexibility.

(3) Bridges in a mountainous city vary in structural type; their structures are very complicated, posing a real challenge to structural design. Those bridge types applicable to mountainous cities include beam bridge, arch bridge, cable-stayed bridge, suspension bridge and composite bridge; this is mainly procured by mountainous cities, and mainly closed to bridge area's geology, topographical condition and sea route navigation level. Geological conditions of different cities vary, and bridge area's river width and navigation requirement vary as 
well; therefore, there are various bridges built.

\section{Difficult Points for Designing Bridges of a Mountainous City}

\subsection{Design of Yudong Yangtze River Bridge}

The bridge is $1,541.6 \mathrm{~m}$ long in total. Its main bridge is a four-span $(145.32+2 \times 260+145.32)$ continuous prestressed concrete rigid frame bridge. Laterally, it is a paralleled twin-deck bridge, bearing 6 lanes and 2 light rail lanes. The main bridge's main girder, structured with single-box dual-chamber section, falls into upper and lower decks; the bridge deck is $41.6 \mathrm{~m}$ wide in total, each half being $20.3 \mathrm{~m}$ in width; its box is $12.9 \mathrm{~m}$ in width, maximum cantilever is $4.8 \mathrm{~m}$, girder at the root is $15.1 \mathrm{~m}$ high, girder at mid-span is $4.6 \mathrm{~m}$ high; all box girders are measured for height as per external edge of external web plate; girder height from closure middle point to cantilever root changes in the form of 1.8 parabola, while the thickness of bottom plate of cast-in-situ section of side span from the closure to support end changes linearly. There are three separated interchanges, two level crossings and one interchange. It started construction formally on December 29, 2004. On December 26, 2008, its upper half bridge opened to traffic, while the lower half bridge opened to traffic on August 13, 2011.

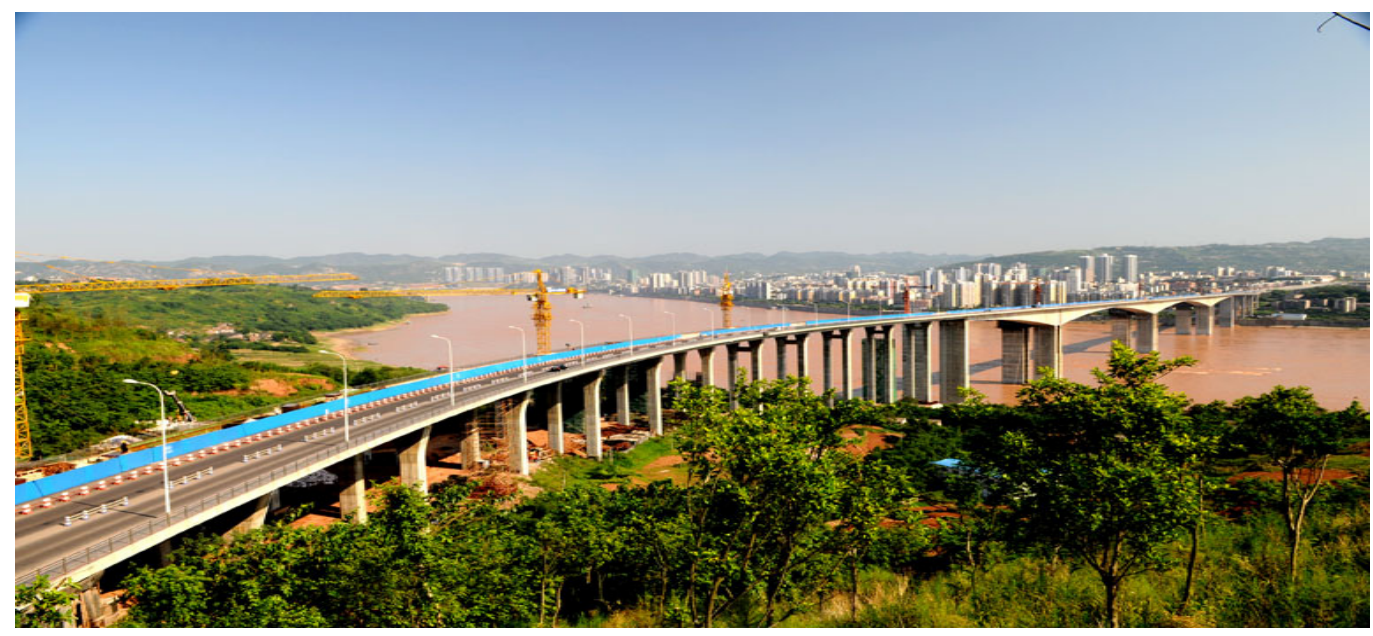

Figure 4. Yudong Yangtze River Bridge

(1) As an ultra-large-span continuous rigid frame bridge for both road and rail traffic, its two main spans are both $260 \mathrm{~m}$, making it at the top list of similar bridges. Its comprehensive technology can be ranked no. 1 in continuous rigid frame bridges.

(2) For the first time, this rigid frame bridge bears automobile and light rail, but with asymmetrical structural section and load. The bridge is $41.6 \mathrm{~m}$ wide, which enables it to be no. 1 among Yangtze River Bridges.

(3) At the main piers, bed rock is complete, but cracks develop. Therefore, if extended foundations are adopted completely, then their large dimension would cause heavy excavation, which is not economic; besides, erosion of cracked bed rock by river water can have adverse impact to the bridge; but if it is designed as per normal pile group foundation, its work for pile foundation will increase; to make full use of bedrock bearing stratum under pile cap, it's better to coordinate external force distribution as per pile and bed rock, that is to say, to consider the combined action of pile cap and pile foundation.

(4) Thickness of bottom plate of 0-9 section changes from $2.2 \mathrm{~m}$ to $1.5 \mathrm{~m}$, gradually. The box girder is constructed with $\mathrm{C} 60$ concrete. In order to prevent temperature crack caused by heat of hydration, cooling pipes are added in bottom plate, which is the first time.

(5) Design requirements are as follows to prevent crack of block no.: (1)The connecting bracket between double-limb piers has certain capacity of adapting to concrete shrinkage to prevent cracking of bottom plate due to constraint; (2) When block no. 0 is poured in multiple times, exert temporary prestress and at the same time, set strengthened circular steel bars at connecting parts of different layers to prevent cracking due to interlayer load and desynchronized shrinkage of new and old concrete surfaces; (3) In design structure, D8 crack control mesh reinforcement is added and polypropylene fiber is mixed into concrete to effectively prevent cracking of block 0 .

(6) Add H-shaped steel into double-limb thin wall pier and hollow interface pier: (1) Replace H-shaped steel 
with main bars of partial pier, which reduces steel bar's set density and is easy for concrete pouring; (2) $\mathrm{H}$-shaped steel already installed in place can be used as skeleton to ensure the stability during construction of main bar of pier; (3) Set H-shaped steel surrounding the pier externally to strengthen the anti-ship collision action of pier and possibly enhance anti-shock capacity of pier.

(7) Only the main bridge is set in the whole riverbed scope, where there are only three T-type pier and 2 junction piers. For this reason, there are good unobstructed sights and multiple bridge holes under the bridge; two main spans are helpful for ships at Foeryan Wharf at the $1.2 \mathrm{~km}$ of the upper stream to navigate and change direction; only main piers are set in the river for the cause of bridge collision resistance.

(8) Web plate and bottom plate vent hole are set longitudinally for each box girder segment; the junction pier is set into pillar pier cap shape, with good ventilation effect; these are good for reducing the temperature between inside and outside box temperature, improving structural load bearing, and promoting the working environment for post maintenance inside the box.

(9) For No. 0 beam section, the concrete can reach up to $1,638 \mathrm{~m} 3$, making it the largest no. 0 beam section in the world; the cantilever casting section is up to $510 \mathrm{t}$ in weight, becoming the cantilever casting section of the highest weight.

(10) Precamber is set as per the equation (constant load (prestressing force) + live load + span length/1000); concrete shrinkage and creep are calculated as per 20 years, and then properly adjusted as per relevant standards and in combination with down-warping phenomena of other similar bridges. Meanwhile, to prevent insufficient comprehensive stress reserve due to excessive actual comprehensive stress and similar causes, try to maintain the section at the comprehensive stress above $1 \mathrm{MPa}$ under any adverse load in design; besides, use backed beam hole to leave adequate leeway for post adjustment of prestressing tendon.

\subsection{Key Technologies in Designing Caiyuanba Yangtze River Bridge}

\subsubsection{Y-type Rigid Frame System of Space}

The bridge scheme dexterously conceives a combined structural system of rigid frame, steel truss girder and tied arch by making full use of the features of strong main beam required for "road-rail use" and basing upon field condition, structural load bearing and material feature; one pair of side span prestressed concrete rigid frames and one mid-span steel box handle-basket arch's three relatively separated substructure are connected into $420 \mathrm{~m}$ tie rod arch through mid-span tie rod and side-span tie rod. As to side-span's Y-type concrete rigid frame, because of cancellation of supporting column below the main beam and linearization of Y-type cantilever, its load bearing features has changed from the features of arch to beam features and the member bar's load bearing status has changed from "mainly under pressure" to "mainly under bending"; its structural design has changed fundamentally, with prestressed structure adopted; especially, to realize the space's handle-basket arch structure, Y-type rigid frame is also designed to a space structure with front and back cantilever ends adducted on the plane surface and torsion of cantilever surface. Y-type rigid frame primarily comprises front and back cantilevers, main crossbeam, front and back secondary crossbeams, front and back main crossbeams, and tie rod cable anchoring part; set heteromorphic transition block on the op of main pier and rigid frame bottom; transition block cross-bridge connects to rigid frame laterally, while internal and external lateral faces are curved. The rigid frame's front and back cantilevers are of thin-walled hollow structure with variable cross section; on the front end of the front cantilever, tie rod cable anchorage element and one front secondary crossbeam; tie rod anchorage parts are separately set at the anchorage points of side-span and mid-span tie rod; the front secondary crossbeam is an important component to keep Y structure space's stability, share Y structure's lateral component force, and set pivot point sling for the cross point between trussed girder and Y structure; as to back cantilever's end, tie rod anchorage structure is set at the solid part of side pier top, at anchorage end of side-span tie rod, and meanwhile, vertical prestressed tie rod is also set to connection the back cantilever end to side pier; this tie rod makes it possible to exert active control over rigid construction and internal force after bridge formation. On the top of the two piers upstream and downstream, main crossbeams of hexagonal gemstone type are set to link together the main pier and both sides' rigid frame.

The Y-type steel structure system of this space, get good shape, stressing definite, complete functions, the precision and technical requirements of the design and construction are very high.Its implementation will be important grarantee of the accurate location of steel box arch rib, the effective of steel truss main girder, the effective force application of The whole bridge tie bar.

\subsubsection{Steel and Mixed Contact Design of Y-Type and Arch Rib Joint Part}

In the bridge construction, with the improvement of using function, the increase of spanning ability, the 
optimization of the structural system, give full play to the material properties, realize optimal combination of the structure and reduce the cost, the segment combination of the material

is the inevitable development trend of bridge construction in the future. The arch rib of Caiyuanba Yangtze River Bridge using steel box structure of equal section, so there must be a transition junction between steel box and Y-type rigid frame system, that is the Steel and mixed contact, is another key to bridge structure. The contact should not only bearing great pressure and repeated moment after the completed bridge, and resistance greater construction load internal force, steel mixed materials have different material characteristics, the effective combination of different materials and the reliability of joint force are very important, Rationality design of the contact directly affects the use of state and structure safety of the main arch rib and bridge.

\subsubsection{The Design of Large Segment Whole Steel Truss Girder}

At present, the construction of large span steel truss bridges in our country basically adopt the member assembly system erection, while the Chongqing Caiyuanba Yangtze River bridge first adopted the design idea of integral girder block in domestic, Where a standard section for $16 \mathrm{~m}$, width of about $40 \mathrm{~m}$ long steel truss girder integral segment as the basic unit of site assembly, requested the segment rods, beams, contact, orthotropic bridge deck are assemble in our factory, then shipped to the construction site hoisting splicing. This whole section design, will make a lot of site bar splicing can achieve inside the factory, which can guarantee the quality of structure within the segment, reduce a lot of bar splicing process, speed up the construction site of frame beam, the increase in the construction site's ability to fight bad weather.

\subsection{Technical Difficulties of Zhongzhou Yangtze River Bridge}

(1) Deep water foundation (foundation water depth $25 \mathrm{~m}$ ), and failure of side span counter-balance weight of balanced anchor box, auxiliary pier and temporary pier, are main technical difficulties of the main bridge. During construction, the mid-span of double cantilever reaches $216 \mathrm{~m}$ and the side span reaches $194 \mathrm{~m}$ and side span reaches 194m; such a large double cantilever status is rarely seen in China, which enables its design and construction difficulty to be higher than general stayed cable.

(2) The main beam's side span weight is exerted by gradual addition of wide ribbed plate.

(3) The main beam's temporary consolidation bracket separates the main beam from the main tower with steel plate, but combines them into an entity through external prestressing tendon and sandglass bracket; at the closing of main span, unlease external prestressing tendon and sandglass bracket to remove longitudinal constraint of the main beam.

(4) After closing of the main span, adjust the force of the last several pairs of stayed-cable to reduce temporary pre-press weight at mid span closing and lower the closing difficulty.

(5) The main tower pier is $247.5 \mathrm{~m}$ high, next only to Sutong Yangtze River Bridge. The diameter of double wall steel cofferdam adopted for the main tower's foundation construction is 36 , enabling this bridge to be ranked as No.1 of bridges of similar scale.

(6) The first segment of steel cofferdam and steel box girder is assembled on floating platform and hoisted wholly after consignment into place; afterwards, back from the floating platform and the first segment immerse into water; this reduces construction processes of shore assembly, launch, consignment into place and construction, thus saving time for construction period.

(7) Both steel cofferdam and suspended steel box are sealed twice. Steel cofferdam sealed twice can effectively prevent the leakage of bottom concrete; suspended steel box back-sealed for the first time can completely isolate water in suspended water box and river water, while the concrete for secondary bottom sealing can make full use of water buoyancy; water drawing can be used to substitute for concrete weight to reduce rod's load and lower the difficulty for bottom sealing construction. Sealing for twice lowers technical difficulty of the critical step of cofferdam.

(8) When the water storage of the Three Gorges' Reservoir reaches $175 \mathrm{~m}, 10,000$-ton class vessels can sail to Chongqing directly, so there can be higher risk of collision between vessel and bridge. The Ministry of Communications and relevant department of Chongqing City have performed "Ship Collision Resistant Measure Design and Early Warning System Study of Piers of Cross-River Bridge in the Three Gorges Reservoir Region", and set floating casing box anti-collision design for piers with higher collision risks. The bridge can bear the impact force up to 2,765 tons, so it is the bridge with the highest anti-collision capacity in Chongqing City.

\section{Conclusion}

It's not simple to build a bridge in a mountainous region. It's more difficult to build a bridge in a mountainous 
city, because of impacts and requirements of a mountainous city in, among other factors, landform, hydrometeorology, building features, comprehensive pipe network, historical humanism, overall scene and overall planning. Why are many existing large-span bridges in a mountainous city recognized as technologically leading ones in China, even in the world? This is not that constructors only pay attention to the breakthrough of technical rank, but because they overcome difficulties above.

\section{References}

Airong, C., Yong, S., \& Feng, Q. (2005). Bridge Modeling . Beijing: China Communications Press, 26-31.

Fan, L. C. (2001). Bridge Construction . First Version Beijing: China Communications Press.

Hua, Y. S. (2011). Chongqing Caiyuanba Yangtze River Bridge. Chongqing. Publishing House.

Li, B., \& Yu, W. (2008). Briefly Discussion of Bridge Construction Technology of Mountain Region. Shanxi Building, 34(31).

Sun, J. S. (2011). Bridge Annals of Chongqing. Chongqing: Chongqing University Press, 94-175.

Wang, F. M., \& Luo, Q. (2002). Discussion on designs and considratios of city bridges according to construction of Chongqing Yuao Bridge.Technology of Highway and Transport, (3), 33-34.

Wang, H., \& Bao,Y. L. (2011). Urban Bridge Planning and Design. Science \& Technology Association Forum.

Wei, Y. (2012). Bridge Position Selection in Bridge Design. Technology Innovation and Application.

Xiang, Z. F. (2008). Study on Chongqing Bridge Construction Level and Feature. Chongqing Jiaotong University.

Zhai, C. X. (2012). Study on Traffic Characteristics and Development Strategy of Group City Taking as an example . Journal of Chongqing Jiaotong University: Social Sciences Edition, 12(12), 9-11.

Zhang, J. (2009). Introduction to Chongqing Jiahua Bridge. Technology of Highway and Transport, (5), 153-155.

\section{Copyrights}

Copyright for this article is retained by the author(s), with first publication rights granted to the journal.

This is an open-access article distributed under the terms and conditions of the Creative Commons Attribution license (http://creativecommons.org/licenses/by/3.0/). 